\title{
Avaliação da Folha e do Colmo de Topo e Base de Perfilhos de Três Gramíneas Forrageiras. 2. Anatomia 1
}

\author{
Domingos Sávio Queiroz ${ }^{2}$, José Alberto Gomide ${ }^{3}$, José Maria ${ }^{3}$
}

RESUMO - A proporção de tecidos, o grau de correlação linear desta característica com a digestibilidade in vitro da matéria seca (DIVMS) e sua composição química foram determinadas em seções transversais das frações botânicas, lâmina e bainha foliares e colmo, amostrados no topo e na base de perfilhos de capim-elefante (Pennisetum purpureum, cv. Mott), capim-setária (Setaria anceps, cv. kazungula) e capim-jaraguá (Hyparrhenia rufa). O capim-jaraguá, com maior proporção de bainha parenquimática dos feixes (BPF) na lâmina foliar e de tecido vascular lignificado (TVL) e esclerênquima (ESC) na lâmina e bainha foliares, apresentou proporção de tecidos menos compatível à de uma forrageira de alto valor nutritivo, em comparação ao capim-elefante e capim-setária. As lâminas foliares caracterizaram-se por apresentar alta proporção de epiderme e baixa proporção de ESC, TVL e células parenquimáticas (CPA) em relação à bainha foliar e ao colmo. A proporção de ESC mostrou correlação negativa com a DIVMS da lâmina foliar de topo, do colmo e do total das frações do perfilho. A proporção de CPA correlacionou positivamente com a DIVMS da bainha foliar, $r=0,68$, enquanto a proporção de TVL apresentou correlação positiva com a DIVMS, quando todas as frações do perfilho foram consideradas, $r=0,31$. As proporções de BPF, TVL e ESC correlacionaram positivamente com os teores de fibra em detergente neutro e fibra em detergente ácido das forrageiras, enquanto as proporções de mesofilo e epiderme apresentaram correlação negativa.

Palavras-chave: anatomia, correlação linear, Hyparrhenia rufa, Pennisetum purpureum, proporção de tecidos, Setaria anceps, valor nutritivo

\section{Evaluation of Top and Bottom Leaf and Stem Fractions from Tiller of Three Forage Grasses. 2. Anatomy}

\begin{abstract}
The tissue proportions, the degree of simple linear correlation of this characteristics with the in vitro dry matter disappearance (IVDMD) and their chemical composition were determined in transversal sections of the botanical fractions, leaf blades and sheath and stem sampled from the top and bottom tillers of dwarf elefantgrass (Pennisetum purpureum, Schumach cv. Mott, setariagrass (Setaria anceps, Stapf ex Massey cv. Kazungula)) and jaraguagrass (Hyparrhenia rufa, Nees Stapf). The jaraguagrass, with high percentage of parenchyma bundle sheath (PBS) in its leaf blade and lignified vascular tissue (LVT) and sclerenchyma (SCL) in the leave blades and sheath, presented a less compatible proportion of tissues with a high nutritive forage value, as compared with dwarf elefantgrass and setariagrass. The leaf blades characterized by showing higher epidermis proportion, lower proportion of SCH, LVT and parenchymal cells (PCA) in relation to leaf sheath and stem. The proportion of SCH negatively correlated with IVDMD of the leaf blade from the top of the tiller, stem, and the total tiller fractions. The proportion of PCA positively correlated with IVDMD of the leaf sheath, $r=0,68$, while the proportion of LVT presented a positive correlation with IVDMD, when all tiller fractions were considered, $\mathrm{r}=0.31$. The proportions PBS, LVT and SCH positively correlated with the neutral detergent fiber and acid detergent fiber content of the forages, while the proportions of mesophyll and epidermis showed a negative correlation.
\end{abstract}

Key Words: anatomy, linear correlation, Hyparrhenia rufa, Pennisetum purpureum, tissue proportion, Setaria anceps, nutritive value

\section{Introdução}

As gramíneas são constituídas por um complexo arranjo de folhas, colmo, inflorescência e raízes, cada fração formada de tecidos designados para funções específicas. Tecidos individuais diferem química e fisicamente, dependendo de seu papel de assimilação, transporte, sustentação, acúmulo de reservas etc. A organização estrutural, ou anatomia dos ór- gãos da planta, e seus tecidos constituintes, além de influenciarem o consumo da forragem pelo animal, em razão do efeito que produzem sobre a facilidade de fragmentação das partículas da forrageira, a natureza das partículas produzidas e sua taxa de passagem pelo rúmen, influem também na digestibilidade da parede celular, proporcionando maior ou menor acessibilidade de seus polissacarídeos aos microrganismos do rúmen (WILSON, 1993).

\footnotetext{
1 Parte da Tese de Doutorado em Zootecnia do primeiro autor, apresentada a UFV.

2 Pesquisador da EPAMIG/CTZM, Casa 46, Vila Gianetti, Viçosa-MG. E-mail: dqueiroz@mail.ufv.br

3 Professor da UFV-Viçosa-MG. E-mail: jagomide@mail.ufv.br
} 
A relação entre a anatomia da folha e do colmo, medida pela proporção de tecidos, e a composição química da forrageira têm despertado interesse dos pesquisadores. A proporção de tecidos é mais comumente medida como a área relativa em seções transversais das frações da planta. Segundo WILSON (1993), devido ao arranjo paralelo longitudinal das principais estruturas de tecidos, essas medidas aproximam-se bem do volume de cada tipo de tecido, exceto para folhas de leguminosas, em função de sua venação reticulada. Embora não haja grande número de trabalhos explorando tais correlações, resultados apresentados em WILKINS (1972), WILSON et. al. (1983), WILSON e HATTERSLEY (1989) e WILSON et. al. (1989a) mostram correlações altamente significativas entre entidades nutritivas e proporção de tecidos.

De modo geral, a proporção de mesofilo relaciona-se positivamente com a digestibilidade e negativamente com o teor de parede celular. As proporções de bainha parenquimática dos feixes, tecido vascular e esclerênquima, ao contrário, relacionam-se negativamente com a digestibilidade e positivamente com o teor de parede celular. A epiderme não tem apresentado correlações consistentes. Assim, parece evidente o papel da anatomia sobre o aproveitamento das forrageiras pelos ruminantes. Os tecidos formados por células de parede celular espessada, que sofrem lignificação, causam a maioria dos problemas da baixa utilização da energia bruta da forragem. A acessibilidade aos carboidratos da parede celular pelos microorganismos do rúmen é limitada não só pela química da parede, mas também pelo arranjo estrutural das células dentro de cada tecido e dos tecidos dentro de cada fração da planta (WILSON e MERTENS, 1995). Entretanto, o volume de informações produzidas é pequeno e o número de espécies avaliadas ainda é reduzido.

Assim, estudo da anatomia da forragem, juntamente com o estudo da composição química e da digestibilidade, pode colaborar para aumentar o grau de conhecimento sobre os fatores que limitam a utilização das forrageiras pelos ruminantes.

O objetivo deste trabalho foi avaliar as características anatômicas de lâmina, bainha e colmo amostrados no topo e base do perfilho, de três gramíneas forrageiras, em duas estações de crescimento, bem como suas correlações com a composição química e a digestibilidade in vitro da matéria seca destas forrageiras.

\section{Material e Métodos}

Foram estudadas as gramíneas forrageiras capim-jaraguá (Hyparrhenia rufa Nees Stapf), capim-setária (Setaria anceps Stapf ex Massey cv. kazungula) e capim-elefante (Pennisetum purpureum Schumach var. Mott). O experimento foi conduzido em área do Departamento de Zootecnia do Centro de Ciências Agrárias da Universidade Federal de Viçosa, Minas Gerais conforme descrito em QUEIROZ et al. (2000).

Para as avaliações anatômicas, 20 perfilhos tomados ao acaso foram desmembrados nas frações lâmina, bainha e o respectivo entrenó da última folha recém-expandida (topo do perfilho) e de uma folha adulta em início de senescência (base do perfilho). Da porção mediana da lâmina, bainha e entrenó de topo e base do perfilho, respectivamente, foi tirado um segmento de aproximadamente $1 \mathrm{~cm}$ e imediatamente colocado em fixador FAA 70 (formol a 40\%, $5 \mathrm{~mL}$; álcool a 70\%, $90 \mathrm{~mL}$ e ácido acético glacial, $5 \mathrm{~mL}$ ), em uma proporção aproximada, volume do fixador/volume de tecido vegetal, de 20 a 30 vezes.

$\mathrm{O}$ material vegetal conservado no fixador foi submetido a vácuo por aproximadamente 30 minutos para retirada de todo o ar do material. Em seguida, quatro segmentos da lâmina foliar e dois da bainha e do colmo, de topo e base do perfilho, respectivamente, em cada estação, foram tomados ao acaso e submetidos à série alcoólica (etileno-glicol-monoetiléter, álcool absoluto, n-propanol e n-butanol) para desidratação. Ao final da série alcóolica, os materiais foram embebidos em metacrilato (JB-4) e, após várias trocas, procedeu-se à polimerização para confecção de bloquinhos para microtomia (FEDER e O'BRIEN, 1968; GLAUERT, 1981). Utilizou-se um micrótomo rotativo, em que seções transversais de 8 a $12 \mu \mathrm{m}$ de espessura, dependendo do material, foram obtidas e montadas em lâminas permanentes, coradas com azul de anilina por 2 a 3 minutos.

Com o uso de um projetor de lâminas (BIOTEC), sob uma mesa de 1,20 m de altura, com tampo de vidro transparente, as lâminas foram projetadas em uma folha de papel vegetal e o contorno dos tecidos delineado com o uso de caneta nanquim, com pena de $0,3 \mathrm{~mm}$. Os tecidos delineados foram: epidermes abaxial e adaxial (EPI), mesofilo ou parênquima clorofiliano (MES) esclerênquima (ESC), bainha parenquimática dos feixes (BPF), tecido vascular 
lignificado (TVL) e células parenquimáticas ou parênquima não-clorofiliano (CPA). As medidas foram obtidas na porção mediana, entre a nervura central e a margem da folha, entre dois grandes feixes vasculares, incluindo um deles, para a lâmina e bainha da folha. No colmo, definiu-se, ao acaso, uma região entre o centro do colmo e a epiderme. Na definição dos tecidos, observou-se que, em algumas seções da bainha da folha, havia a presença de cloroplastos em algumas células em volta dos feixes vasculares. Dada a baixa concentração de cloroplastos e a ocorrência particularizada somente em algumas seções, estes tecidos foram definidos como células parenquimáticas, em vez de mesofilo, seguindo a sugestão de WILSON (1993).

Com o uso de um scanner de mesa (HEWLETT PACKARD SCAN JET 3C), os desenhos das projeções foram transferidos para um computador 486. Com o uso do software ALDUS PHOTOSTYLER 2.0, cada tecido recebeu uma cor diferente, padronizada para cada tipo de tecido em todas as seções avaliadas. Um novo software, IMAGE 1.0, desenvol- vido pelo Departamento de Informática da UFV, foi usado para calcular a proporção relativa de cada tecido. Pelo programa, obteve-se a área correspondente a cada cor no desenho delineado de cada seção, o que permitiu calcular a contribuição relativa de cada tecido, na área total da seção (Figura 1).

Obtidas as informações anatômicas, os dados foram submetidos à análise de variância por meio do SAS. Devido à ausência de colmo no capim-jaraguá no verão, duas análises de variância foram feitas (ANOVA 1 e ANOVA 2), conforme descrito em QUEIROZ et al.(2000). Para as variáveis proporção de bainha parenquimática dos feixes e de mesofilo, cuja ocorrência se restringe à lâmina da folha, a análise de variância seguiu o modelo:

$\mathrm{Y}_{\mathrm{ijkl}}=\mu+\mathrm{E}_{\mathrm{i}}+\mathrm{I}_{\mathrm{j}}+\mathrm{C}_{\mathrm{k}}+\mathrm{EI}_{\mathrm{ij}}+\mathrm{EC}_{\mathrm{ik}}+\mathrm{IC}_{\mathrm{jk}}+\mathrm{EIC}_{\mathrm{ijk}+} \mathrm{e}_{\mathrm{ijkl}}$ em que

$\mathrm{Y}_{\mathrm{ijkl}}=$ valor da $\mathrm{l}^{\mathrm{a}}$ observação, relativa à $\mathrm{k}^{\underline{\mathrm{a}}}$ estação de crescimento e j $\mathrm{j}^{\mathrm{a}}$ inserção; da i⿳亠口冋 espécie;

$\mu \quad=$ média geral;

$\mathrm{E}_{\mathrm{i}} \quad=$ efeito da $\mathrm{i}^{\mathrm{a}}$ espécie, sendo $\mathrm{i}=1,2,3$;

$\mathrm{I}_{\mathrm{j}} \quad=$ efeito da $\mathrm{j}$ inserção, sendo $\mathrm{j}=1,2$;

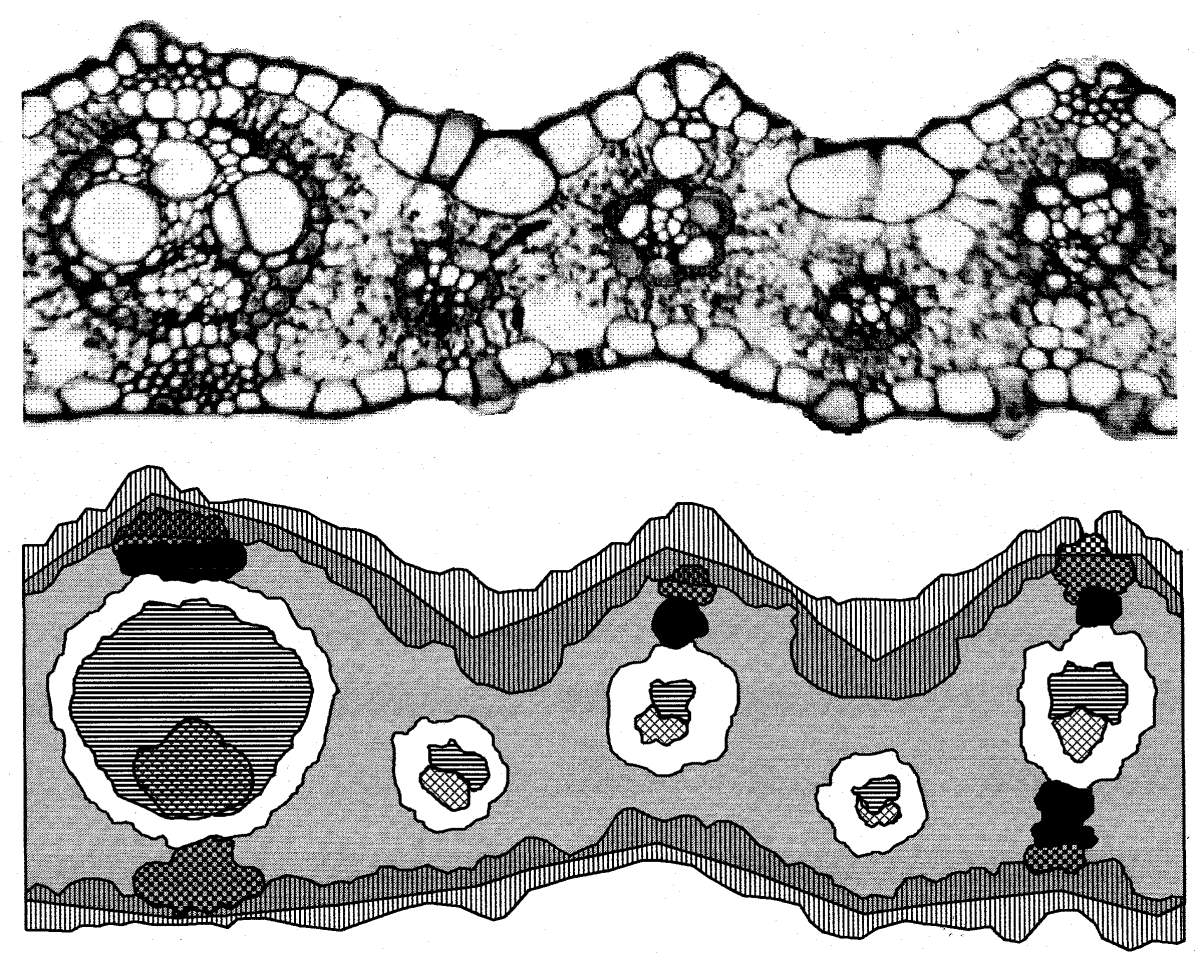

Figura 1 - Fotomicrografia da seção transversal da lâmina foliar recém-expandida de capim-elefante cv. Mott e sua projeção com os tecidos em destaque.
四 epiderme
目 tecido vascular lignificado
圈 esclerênquima
$\square$ bainha parenquimática dos feixes
floema mélulas

Figure 1 - Photomicrography of tranverse section of elephantgrass cv. Mott recently expanded leaf blade and its projection with the tissues in evidence.

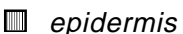
彗 lignified vascular tissue

으․ sclerenchyma 
$\mathrm{C}_{\mathrm{k}} \quad=$ efeito da $\mathrm{k}^{\mathrm{a}}$ estação, sendo $\mathrm{k}=1,2$;

$\mathrm{EI}_{\mathrm{ij}}=$ interação dos efeitos da ia espécie com a j $\mathrm{j}^{\mathrm{a}}$ inserção;

$\mathrm{EC}_{\mathrm{ik}}=$ interação dos efeitos da $\mathrm{i}^{\mathrm{a}}$ espécie com a $\mathrm{k}^{\mathrm{a}}$ estação;

ICjk = interação dos efeitos da $\mathrm{j}^{\mathrm{a}}$ inserção com a k ํㅡㄹ estação;

EICijk = interação dos efeitos da i $\mathrm{i}$ espécie com a $\mathrm{j}^{\mathrm{a}}$ inserção com a k $\underline{\mathrm{a}}$ estação; e

$\mathrm{e}_{\mathrm{ijkl}}=$ erro aleatório associado a cada observação, e $=1,2, \ldots 24$.

As interações significativas foram desdobradas e as médias comparadas pelo teste de Newman Keuls, a $5 \%$ de probabilidade, pelo SAEG. Coeficientes de correlação linear entre as características anatômicas e a composição química e a digestibilidade in vitro foram calculados considerando todas as frações do perfilho, bem como para a lâmina foliar de topo, lâmina foliar de base, lâmina foliar total, bainha foliar e colmo.

\section{Resultados e Discussão}

Estudos histológicos associados à análise química podem prover base mais segura para explicar as diferenças de digestibilidade entre espécies forrageiras (AKIN, 1989 e WILSON, 1993). Histologicamente, o capim-jaraguá apresentou proporção de tecidos menos compatível à de uma forrageira de alto valor nutritivo. Maiores proporções de TVL e ESC na lâmina e bainha foliares (Tabela 1) e de BPF na lâmina foliar (Tabela 2) foram observadas em capimjaraguá em comparação ao capim-setária e capimelefante. Estes tecidos apresentam parede celular espessada, lignificada, estando freqüentemente associados à fração lentamente digestível e ao teor de fibra da forrageira (AKIN, 1989; WILSON, 1993).

A proporção de mesofilo apenas exibiu diferença $(\mathrm{P}<0,01)$ entre espécies. A mais alta proporção de mesofilo foi observada no capim-elefante, $39,5 \%$, em relação ao capim-jaraguá e capim-setária, que, com 35,2 e 32,7\% de mesofilo na seção transversal da lâmina foliar, respectivamente, não diferiram entre si. O capimelefante destacou-se pela mais elevada proporção de mesofilo na lâmina foliar e células parenquimáticas na bainha foliar. As CPA, que constituem o tecido predominante na seção transversal da bainha foliar, conforme WILSON (1976) e AKIN et al. (1977), chegaram a representar quase $85 \%$ da área de seções da bainha das folhas do topo do capim-elefante (Tabela 1).

Em comparação ao capim-jaraguá e capim-elefante, a folha de capim-setária apresentou mais baixa proporção de BPF na lâmina foliar e de ESC e TVL na lâmina e bainha foliares, características desejáveis, ao se considerar a associação positiva desses tecidos com a fração lentamente digestível e os teores de fibra da forragem (AKIN, 1989; WILSON, 1993). Outro tecido da folha de capim-setária que se destacou por sua elevada participação foi a epiderme, sendo aproximadamente $40 \%$ maior que a observada no capim-elefante e capim-jaraguá (Tabela 1). Embora a parede periciclinal externa da epiderme apresente resistência à digestão, por ser cutinizada e lignificada, a composição da parede celular interna eqüivale à do mesofilo (CHESSON et al., 1986), sendo rapidamente digerida (HANNA et al., 1973). WILSON et al. (1991) verificaram intensidade de digestão equivalente entre a epiderme e o mesofilo em seções transversais de Panicum maximum e Cynodon dactylon incubadas in vitro.

Lâminas foliares caracterizaram-se por apresentar alta proporção de epiderme, baixa proporção de esclerênquima, TVL e CPA em relação à bainha e ao colmo. Mesofilo e BPF foram tecidos encontrados exclusivamente na lâmina foliar, embora a literatura registre a presença desses tecidos na bainha foliar (AKIN et al., 1977). Entretanto, WILSON (1993) sugere que na bainha foliar estes tecidos devem ser classificados como parênquima não-clorofiliano, pela baixa concentração de cloroplastos e ocorrência restrita a algumas bainhas, fato observado no presente trabalho.

A proporção de tecidos das frações do perfilho foi fortemente influenciada pelo nível de inserção. Observou-se a formação de uma banda de esclerênquima abaixo da epiderme do colmo de capim-setária com o amadurecimento, decorrente do espessamento da parede celular das células parenquimáticas, fato caracterizado pela observação de $9,6 \%$ de esclerênquima no colmo de base dessa espécie (Tabela 1). A grande variação entre colmos de topo e base decorre da natureza acrópeta de seu desenvolvimento. Embora amplamente documentada em gramíneas forrageiras (AKIN et al., 1977; HANNA et al., 1976; WILSON et al., 1989b; WILSON et al., 1991; e WILSON, 1994), esta característica não foi observada na base do colmo de capim-elefante cv. Mott, cultivar que apresentou lento alongamento do colmo durante período de rebrota avaliado.

A proporção de células parenquimáticas, tecido predominante na bainha foliar, foi acentuadamente reduzida na bainha foliar da base do perfilho, decorrente da formação de lacunas, fato observado nas três gramíneas. CHERNEY e MARTEN (1982), em trigo, 
Rev. bras. zootec.

Tabela 1 - Proporção (\% da seção transversal) de epiderme, células parenquimáticas, tecido vascular lignificado e esclerênquina, em perfilhos de capim-elefante (CE), capim-setária (CS) e capimjaraguá (CJ), segundo as frações e os níveis de inserção

Table 1 - Proportion (\% of transverse sections) of epidermis, parenchymal cells, lignified vascular tissue and sclerenchyma, in elephantgrass (EG), setariagrass (SG) and jaraguagrass (JG) according to the tiller fractions and the insertion levels

\begin{tabular}{|c|c|c|c|c|c|c|}
\hline \multirow{3}{*}{$\begin{array}{l}\text { Espécie } \\
\text { Specie }\end{array}$} & \multicolumn{6}{|c|}{ Fração do perfilho (Tiller fraction) } \\
\hline & \multicolumn{2}{|c|}{ Lâmina (Blade) } & \multicolumn{2}{|c|}{ Bainha (Sheath) } & \multicolumn{2}{|c|}{ Colmo $($ Stem $)$} \\
\hline & Topo (Top) & Base (Bottom) & Topo (Top) & Base (Bottom) & Topo (Top) & Base (Bottom) \\
\hline & \multicolumn{6}{|c|}{ - } \\
\hline $\mathrm{CE}(E G)$ & $33,9^{\mathrm{Bb}}$ & $36,5^{\mathrm{Ba}}$ & $4,7 \mathrm{Ca}$ & $5,2^{\mathrm{Ca}}$ & $1,0^{\mathrm{Aa}}$ & $0,6^{\mathrm{Ba}}$ \\
\hline $\mathrm{CS}(\mathrm{SG})$ & $49,0^{\mathrm{Aa}}$ & $48,1^{\mathrm{Aa}}$ & $13,2^{\mathrm{Ab}}$ & $16,0^{\mathrm{Aa}}$ & $1,8^{\mathrm{Aa}}$ & $3,6^{\mathrm{Aa}}$ \\
\hline \multirow[t]{2}{*}{$\mathrm{CJ}(J G)$} & $34,2^{\mathrm{Ba}}$ & $35,1^{\mathrm{Ba}}$ & $10,1^{\mathrm{Ba}}$ & $11,2^{\mathrm{Ba}}$ & - & - \\
\hline & \multicolumn{6}{|c|}{--------------------Célula parenquimática (Parenchymal cell), \% --------------------- } \\
\hline $\mathrm{CE}(E G)$ & $2,5^{\mathrm{Aa}}$ & $1,4^{\mathrm{Aa}}$ & $84,8^{\mathrm{Aa}}$ & $65,7^{\mathrm{Ab}}$ & $75,9^{\mathrm{Bb}}$ & $89,5^{\mathrm{Aa}}$ \\
\hline $\mathrm{CS}(S G)$ & $2,1^{\mathrm{Aa}}$ & $2,6^{\mathrm{Aa}}$ & $72,1^{\mathrm{Ba}}$ & $51,1^{\mathrm{Bb}}$ & $84,0^{\mathrm{Aa}}$ & $70,7^{\mathrm{Bb}}$ \\
\hline \multirow[t]{2}{*}{$\mathrm{CJ}(J G)$} & $4,1^{\mathrm{Aa}}$ & $2,7^{\mathrm{Aa}}$ & $72,5^{\mathrm{Ba}}$ & $48,9^{\mathrm{Bb}}$ & - & - \\
\hline & \multicolumn{6}{|c|}{---------------- Tecido vascular lignificado (Lignified vascular tissue), \% ----------------- } \\
\hline $\mathrm{CE}(E G)$ & $6,9^{\mathrm{Aa}}$ & $4,4^{\mathrm{Bb}}$ & $5,3^{\mathrm{Ca}}$ & $3,6^{\mathrm{Bb}}$ & $20,1^{\mathrm{Aa}}$ & $9,2^{\mathrm{Ab}}$ \\
\hline $\mathrm{CS}(S G)$ & $3,2^{\mathrm{Ba}}$ & $2,7 \mathrm{Ca}$ & $8,5^{\mathrm{Ba}}$ & $4,3^{\mathrm{Bb}}$ & $12,4^{\mathrm{Ba}}$ & $9,7^{\mathrm{Aa}}$ \\
\hline \multirow[t]{2}{*}{$\mathrm{CJ}(J G)$} & $7,4^{\mathrm{Aa}}$ & $6,9^{\mathrm{Aa}}$ & $11,0^{\mathrm{Aa}}$ & $11,0^{\text {Aa }}$ & - & - \\
\hline & \multicolumn{6}{|c|}{-------------------------------Esclerênquima (Sclerenchyma), \% ------------------------------- } \\
\hline $\mathrm{CE}(E G)$ & $1,7^{\mathrm{Aa}}$ & $0,8^{\mathrm{Aa}}$ & $4,1^{\mathrm{Aa}}$ & $2,8^{\mathrm{Ba}}$ & $0,0^{\mathrm{Aa}}$ & $0,0^{\mathrm{Ba}}$ \\
\hline $\mathrm{CS}(S G)$ & $2,1^{\mathrm{Aa}}$ & $1,3^{\mathrm{Aba}}$ & $4,0^{\mathrm{Aa}}$ & $2,7^{\mathrm{Ba}}$ & $0,0^{\mathrm{Aa}}$ & $9,6^{\mathrm{Ab}}$ \\
\hline $\mathrm{CJ}(\mathrm{JG})$ & $2,4^{\mathrm{Aa}}$ & $2,3^{\mathrm{Ba}}$ & $5,2^{\mathrm{Aa}}$ & $5,0^{\mathrm{Aa}}$ & - & - \\
\hline
\end{tabular}

Médias seguidas de letras diferentes, minúsculas nas linhas, em cada fração do perfilho e maiúsculas na coluna, em cada variável são diferentes $(P<0,05)$ pelo teste Newman-Keuls.

Means followed by different letters, small in the row for each tiller fraction and capital in the column, for each tissue are different $(P<.05)$ by Newman Keuls test.

Tabela 2 - Proporção de bainha parenquimática dos feixes (BPF) em lâminas foliares de capim-elefante, capim-setária e capim-jaraguá, segundo as estações do ano e os níveis de inserção

Table 2 - Parenchyma bundle sheath (PBS) proportion of leaf blade of elephantgrass, setariagrass and jaraguagrass, according to the season year and insertion levels

\begin{tabular}{|c|c|c|c|c|}
\hline \multirow[t]{2}{*}{$\begin{array}{l}\text { Espécie } \\
\text { Specie }\end{array}$} & \multicolumn{2}{|c|}{$\begin{array}{l}\text { Nível de inserção } \\
\text { Insertion level }\end{array}$} & \multicolumn{2}{|c|}{$\begin{array}{l}\text { Estação do ano } \\
\text { Season year }\end{array}$} \\
\hline & Topo (Top) & Base (Botton) & Verão (Summer) & Outono $($ Fall $)$ \\
\hline & 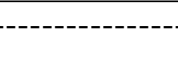 & $\begin{array}{l}\mathrm{BPF}(\% \text { na sec } \\
P B S(\% \text { in tra }\end{array}$ & $\begin{array}{l}\text { o transversal) ---- } \\
\text { erse section) }\end{array}$ & ---- \\
\hline Capim-elefante (Elephantgrass) & $11,9^{\mathrm{Ba}}$ & $7,9^{\mathrm{Bb}}$ & $11,4^{\mathrm{Ba}}$ & $10,3^{\mathrm{Bb}}$ \\
\hline Capim-setária (Setariagrass) & $8,9^{\mathrm{Ca}}$ & $7,0^{\mathrm{Cb}}$ & $7,6^{\mathrm{Ca}}$ & $8,3^{\mathrm{Ca}}$ \\
\hline Capim-jaraguá ( Jaraguagrass) & $13,3^{\mathrm{Aa}}$ & $12,7^{\mathrm{Aa}}$ & $12,3^{\mathrm{Ab}}$ & $13,8^{\mathrm{Aa}}$ \\
\hline
\end{tabular}

Médias seguidas de letras diferentes, maiúsculas nas colunas e minúsculas nas linhas, entre os níveis de inserção ou as estações de crescimento são diferentes $(P<0,05)$ pelo teste Newman-Keuls.

Means followed by different letters, small in the row and capital in the column, between the insertion levels or season year are different $(P<.05)$ by Newman Keuls test.

aveia e cevada, e WILKINS (1972), em quatro gramíneas de clima temperado, citam a presença de lacunas na bainha foliar e sua expansão com a maturidade.

Lâminas foliares do topo do perfilho apresentaram maior proporção de esclerênquima, TVL (Tabela 1) e BPF (Tabela 2), que lâminas foliares da base do perfilho, fatos também observados por WILSON (1976) em Panicum maximum var. Trichoglume.

As três espécies mostraram comportamento in- consistente quanto ao efeito da estação do ano sobre as características anatômicas, sendo observados maiores valores $(\mathrm{P}<0,05)$ no verão, em relação ao outono, para a proporção de EPI no topo do perfilho de capim-setária $(22,4 \times 20,3 \%)$; BPF em capim-elefante $(11,4 \times 10,3 \%)$; CPA na bainha foliar de capim-elefante $(77,4 \times 73,0 \%)$; e TVL no colmo de topo $(19,7 \times 12,8 \%)$. Maiores $(\mathrm{P}<0,05)$ valores no outono, relativamente ao verão, foram observados para a proporção de EPI no topo de capim-setária 
(23,6x21,5\%); BPF em capim-jaraguá $(13,8 \times 12,3 \%)$; e CPA na bainha foliar de capim-setária $(64,4 \times 58,8 \%)$. A passagem do estádio vegetativo, no verão, para reprodutivo, no outono, em capim-elefante e capimjaraguá e de início de florescimento, no verão, para vegetativo, no outono, em capim-setária, contribuiu para a inconsistência observada.

Na Tabela 3, são apresentados os coeficientes de correlação entre a DIVMS e as características anatômicas das lâminas e bainhas foliares e do colmo.

Tabela 3 - Correlação entre a digestibilidade in vitro da matéria seca e a proporção de tecidos em frações do perfilho

Table 3 - Correlation between in vitro dry matter disappearance and tissues proportions of tiller fractions

\begin{tabular}{|c|c|c|c|c|c|c|c|}
\hline \multirow[t]{2}{*}{$\begin{array}{l}\text { Fração do perfilho } \\
\text { Tiller fraction }\end{array}$} & \multirow{2}{*}{$\begin{array}{l}\text { Número de } \\
\text { observação } \\
\text { Number of } \\
\text { observation }\end{array}$} & \multicolumn{6}{|c|}{$\begin{array}{l}\text { Tecido } \\
\text { Tissue }\end{array}$} \\
\hline & & $\begin{array}{l}\text { EPI } \\
E P I\end{array}$ & $\begin{array}{l}\text { MES } \\
M E S\end{array}$ & $\begin{array}{l}\mathrm{ESC} \\
\mathrm{SCH}\end{array}$ & $\begin{array}{l}\text { BPF } \\
P B S\end{array}$ & $\begin{array}{l}\text { TVL } \\
L V T\end{array}$ & $\begin{array}{l}\text { CPA } \\
P A C\end{array}$ \\
\hline $\begin{array}{l}\text { Lâmina foliar total } \\
\text { Total leaf blade }\end{array}$ & 24 & 0,05 & 0,08 & 0,12 & $-0,10$ & $-0,08$ & $-0,04$ \\
\hline $\begin{array}{l}\text { Lâmina foliar de topo } \\
\text { Top leaf blade }\end{array}$ & 12 & $-0,06$ & 0,14 & $-0,66 * *$ & $-0,11$ & $-0,10$ & $-0,16$ \\
\hline $\begin{array}{l}\text { Lâmina foliar de base } \\
\text { Bottom leafblade }\end{array}$ & 12 & 0,11 & 0,26 & $-0,22$ & $-0,36$ & $-0,32$ & $-0,25$ \\
\hline $\begin{array}{l}\text { Bainha foliar total } \\
\text { Total sheath blade }\end{array}$ & 24 & $-0,03$ & - & $-0,04$ & - & $-0,08$ & $0,68 * * *$ \\
\hline $\begin{array}{l}\text { Colmo total } \\
\text { Total stem }\end{array}$ & 20 & 0,24 & - & $-0,58 * *$ & - & 0,36 & 0,32 \\
\hline $\begin{array}{l}\text { Todas as frações } \\
\text { Total fractions }\end{array}$ & 68 & $-0,06$ & - & $-0,37 * * *$ & - & $0,31 * *$ & 0,15 \\
\hline
\end{tabular}

EPI (EPI) - epiderme (epidermis), MES (MES) - mesofilo (mesophyl), ESC (SCH) - esclerênquina (sclerenchyma), $\mathrm{BPF}(P B S)$ - bainha parenquimática dos feixes (parenchyma bundle sheath), TVL $(L V T)$ - tecido vascular lignificado (lignified vascular tissue), CPA (PAC) - células parenquimáticas (parenchymal cells).

*** $(\mathrm{P}<0,001) .{ }^{* *}(\mathrm{P}<0,01) .{ }^{*}(\mathrm{P}<0,05)$.

Tabela 4 - Correlação entre a proporção de tecidos e as entidades químicas na lâmina foliar e em todas as frações do perfilho

Table 4 - Correlation between tissues proportions and chemical entities leaf blade and total tiller fractions

$\frac{\text { Table } 4 \text { - Correlation between tissues proportions and chemical entities leaf blade and total tiller fractions }}{\text { Tecido }}$

Tissue

\begin{tabular}{llllll}
\multicolumn{6}{c}{ Tissue } \\
\hline BPF & MES & EPI & ESC & TVL & CPA \\
$P B S$ & $M E S$ & $E P I$ & $S C L$ & $L V T$ & $P A C$ \\
\hline
\end{tabular}

Fibra em detergente neutro

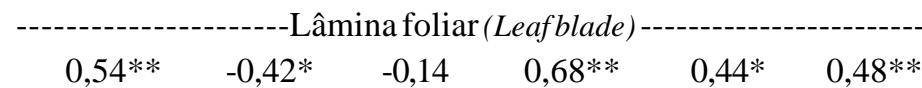

Neutral detergent fiber

Fibra em detergente ácido

$0,79 * * * \quad-0,12 \quad-0,55 * * \quad 0,67 * * * \quad 0,78 * * * \quad 0,56 * *$

Acid detergent fiber

Proteína bruta

Crude protein

Lignina

$-0,78 * * * \quad-0,23 \quad 0,76 * * * \quad-0,41 * \quad-0,86 * * * \quad-0,37 *$

Lignin

$0,50 * * \quad 0,19 \quad-0,52 * * \quad 0,14 \quad 0,52 * * \quad 0,36 *$

Lignin

Fibra em detergente neutro

Neutral detergent fiber

Fibra em detergente ácido

Acid detergent fiber

Proteína bruta

Crude protein

Lignina

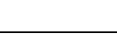

-Todas as frações-

All fractions

Lignin

\begin{tabular}{cccccc} 
& \multicolumn{5}{c}{ All fractions } \\
- & - & $-0,20 *$ & $0,59 * * *$ & $-0,05$ & 0,16 \\
- & - & $-0,16$ & $0,58 * * *$ & $-0,12$ & 0,07 \\
- & - & $0,27 *$ & $-0,51 * * *$ & $0,24 *$ & $-0,23 *$ \\
- & - & $-0,21 *$ & $0,53 * * *$ & 0,03 & 0,08
\end{tabular}

$\mathrm{EPI}(E P I)$ - epiderme (epidermis), MES (MES) - mesofilo (mesophyl), ESC (SCH) - esclerênquima (sclerenchyma), $\operatorname{BPF}(P B S)$ - bainha parenquimática dos feixes (parenchyma bundle sheath), TVL (LVT) - tecido vascular lignificado (lignified vascular tissue), CPA (PAC) - células parenquimáticas (parenchymal cells).

*** $(P<0,001) ;{ }^{* \star}(P<0,01) ;{ }^{*}(P<0,05)$. 
Na bainha foliar, no colmo e no total das frações, não se incluíram as características pertinentes apenas à lâmina foliar, como as proporções de mesofilo e bainha parenquimática dos feixes.

Quando somente dados da lâmina foliar foram considerados, a única característica anatômica a mostrar correlação significativa com a DIVMS foi a proporção de esclerênquima na lâmina foliar de topo, $\mathrm{r}=-0,66(\mathrm{P}<0,01)$. No colmo, quando todas as frações foram consideradas, a proporção de esclerênquima voltou a se destacar, com correlações significativas (Tabela 3). Segundo WILSON (1994), o esclerênquima, embora propicie pequena contribuição em área, freqüentemente produz grande efeito na qualidade da forrageira, em decorrência da grande espessura de sua parede celular.

A proporção de CPA correlacionou-se positiva e significativamente com a digestibilidade in vitro da bainha foliar, $r=0,68(\mathrm{P}<0,01)$. A elevada digestibilidade da bainha de topo, em média $70,6 \%$ para as três gramíneas, aliada à acentuada redução na proporção de CPA com o envelhecimento, decorrente da formação de lacunas, justifica a associação positiva da digestibilidade da bainha foliar com a proporção de CPA.

A proporção de TVL apresentou correlação significativa positiva com a DIVMS, quando todas as frações do perfilho foram consideradas (Tabela 3). Considerando que o TVL é formado por células de paredes espessadas, lignificadas e inertes ao ataque microbiano, esperar-se-ia que esta correlação fosse negativa, conforme observado por WILSON et al. (1983), WILSON e HATTERSLEY (1989), WILSON et al. (1989a). Valores significativamente $(\mathrm{P}<0,05)$ mais elevados de TVL foram observados nas frações de topo relativamente às da base do perfilho em capim-elefante e bainha foliar do capimsetaria. No caso da bainha foliar e do colmo, o estádio ainda meristemático no momento da amostragem conduziu a esta situação, já que o tecido vascular se desenvolve primeiro para depois ocorrer a expansão das células parenquimáticas. Esse comportamento gerou distorção, em que a proporção de TVL se associou positivamente à DIVMS, quando a análise de correlação considerou todas as frações do perfilho. Os trabalhos referidos anteriormente compararam materiais de mesmo estádio de desenvolvimento.

BPF, ESC E TVL proporcionaram correlações altamente significativas, positivas com os teores de FDN, FDA e lignina e negativas com os teores de proteína bruta (Tabela 4). Estes tecidos apresentam parede celular espessada, lignificada, estando freqüentemente associados à fração lentamente digestível e ao teor de fibra da forrageira (WILSON, 1993; AKIN, 1989). As relações observadas neste trabalho, entre a proporção de BPF, TVL e ESC com os teores de FDN, estão em sintonia com aquelas observadas por WILSON et al. (1983) e WILSON et. al. (1989a), ainda que mediante um coeficiente de correlação de magnitude variável.

A proporção de mesofilo apresentou correlação significativa negativa com os teores de FDN na lâmina foliar $(r=-0,42, P<0,05)$, mas não com a DIVMS. Associações significativas entre a proporção de mesofilo e os teores de FDN e a DIVMS têm sido observadas somente para conjunto de dados referentes a gramíneas C3 e C4 (WILSON e HATTERSLEY, 1989; e WILSON et al., 1983).

A proporção de epiderme na lâmina foliar não se associou significativamente à DIVMS, porém correlacionou-se negativamente aos teores de FDA $(\mathrm{r}=-0,55 ; \mathrm{P}<0,01)$ e lignina $(\mathrm{r}=-0,52 ; \mathrm{P}<0,01)$ e positivamente aos teores de proteína bruta $(r=0,76$; $\mathrm{P}<0,001)$. Embora a parede periclinal externa da epiderme apresente resistência à digestão, por ser cutinizada e lignificada, a composição da parede celular interna eqüivale à do mesofilo (CHESSON et al., 1986), sendo rapidamente digerida (HANNA et al., 1973). WILSON et al. (1991) verificaram intensidade de digestão equivalente entre a epiderme e o mesofilo em seções transversais de Panicum maximum e Cynodon dactylon incubadas in vitro. Daí o relacionamento positivo com a proporção de proteína bruta e negativo com lignina e os teores de FDA.

Relativamente ao que se observa na literatura, poucos tecidos apresentaram correlação significativa com a DIVMS. Ao se amostrarem a folha de base em início de senescência e a folha de topo recémexpandida, provocou-se a superposição de dois efeitos, da idade e do nível de inserção, que afetam diferentemente a proporção de tecidos, gerando confundimento que reduziu o potencial da proporção de tecidos como indicadora da digestibilidade. Contribuiu, ainda, a inconsistência entre as gramíneas quanto aos efeitos da estação de crescimento sobre os parâmetros avaliados - efeitos intensificados pela amostragem antecipada do capim-setária.

Ainda assim, tecidos individuais, como o esclerênquima na lâmina foliar e no colmo e CPA na bainha foliar, mostraram potencial como indicadores da digestibilidade, além de altamente associados ao teor de fibra das forrageiras. A proporção de tecidos, técnica escolhida como indicadora da qualidade em 
gramíneas forrageiras no presente trabalho, não deixa dúvidas quanto ao seu potencial, refletido pelos altos coeficientes de correlação obtidos com a digestibilidade e o teor de fibra da forrageira (WILKINS, 1972; WILSON et al., 1983; WILSON et al., 1989b; e WILSON e HATTERSLEY, 1989). Entretanto, a abordagem adotada neste trabalho, em que se avaliaram as espécies e suas frações, os efeitos da estação do ano e do grau de maturidade, acoplado ao efeito do nível de inserção, gerou sobreposição de efeitos com prejuízos ao potencial da metodologia utilizada. Embora em pequeno número, os trabalhos publicados têm mostrado que a proporção de tecidos é uma técnica pouco sensível aos efeitos de alterações de ambiente ou do grau de maturidade sobre a qualidade de gramíneas forrageiras. Avaliações de espessura da parede celular de determinados tecidos ou testes histoquímicos parecem alternativas mais apropriadas para detectar alterações decorrentes do efeito da maturidade e do ambiente sobre a qualidade de gramíneas forrageiras.

Considerando-se a variabilidade de gramíneas forrageiras utilizadas na formação de pastagens no Brasil e o desconhecimento quase total de suas características anatômicas relacionadas ao valor nutritivo, estudos de proporção de tecidos devem considerar o maior número de espécies e a amostragem das frações botânicas do perfilho em mesmo estádio de maturidade. Assim, poder-se-ia ampliar o intervalo de variabilidade e a probabilidade de se obterem coeficientes de correlação mais altos.

\section{Conclusões}

O grau de diferenciação entre espécies, frações do perfilho e níveis de inserção mostrou-se variável, dependendo da característica anatômica considerada.

A proporção de esclerênquima foi a característica anatômica que melhor se correlacionou com a DIVMS.

Correlações positivas altamente significativas foram observadas entre a proporção de BPF, TVL e ESC e os teores de FDN, FDA e lignina das gramíneas, enquanto as proporções de MES e EPI se correlacionaram negativamente.

\section{Referências Bibliográficas}

AKIN, D.E. 1989. Histological and physical factors affecting digestibility of forages. Agron. J., 81(1):17-25.

AKIN, D.E., ROBINSON, E.L., BARTON, II,F.E. et al. 1977. Changes with maturity in anatomy, histochemistry, chemistry, and tissue digestibility of bermudagrass plant parts. J. Agric. Food Chem., 25(1):179-186.
CHERNEY, J.H., MARTEN, G.C. 1982. Small grain crop forage potential: II. Interrelationships among biological, chemical, morphological, and anatomical determinants of quality. Crop Sci., 22(2):240-245.

CHESSON, A., STEWART, C.S., DALGARNO, K. et al. 1986. Degradation of isolated grass mesophyll, epidermis and fibre cell wall in the rumen and by cellulotic rumen bacteria in axemic culture. J. Appl. Bacteriol., 60(4):327-336.

FEDER, N., O'BRIEN, T.P. 1968. Plant microtechnique: some principles and new methods. Am. J. Bot., 55(1):123-124.

GLAUERT, A.M. 1981. Fixation, dehydration and embedding of biological specimens: practical method in electron microcopy. Amsterdan, Biomedical Press. 207p.

HANNA, W.W., MONSON, W.G., BURTON, G.W. 1976. Histological and in vitro digestion study of 1 and 4-week stems and leaves from high and low quality bermudasgrass genotypes. Agron. J., 68(2):219-222.

HANNA, W.W., MONSON, W.G., BURTON, G.W. 1973. Histological examination of fresh forage leaves after in vitro digestion. Crop Sci., 13(1):98-102.

QUEIROZ, D.S., GOMIDE, J.A., MARIA, J. 2000. Avaliação da folha e do colmo de topo e base de perfilhos de três gramíneas forrageiras. I. Digestibilidade in vitro e composição química. Rev. bras. zootec., 29(1):53-60.

WILKINS, R.J. 1972. The potential digestibility of cellulose in grasses and its relationship with chemical and anatomical parameters. J. Agric. Sci., 78(3):457-464.

WILSON, J.R. 1994. Cell wall characteristics in relation to forage digestion by ruminants. J. Agric. Sci., 122(2):173-182.

WILSON, J.R. 1993. Organization of forage plant tissues. In: JUNG, H.G., BUXTON, D.R., HATFIELD, R.D. et al. (Eds.) Forage cell wall structure and digestibility, Madison: American Society of Agronomy, Crop Sci. Society of America, Soil Science Society of America. p.1-32.

WILSON, J.R. 1976. Variation of leaf characteristics with level of insertion on a grass tiller. II. Anatomy. Aust. J. Agric. Res., 27(3):355-364.

WILSON, J.R., HATTERSLEY, P.W. 1989. Anatomical characteristics and digestibility of leaves of Panicum and other grass genera of $\mathrm{C}_{4}$ photosynthetic pathway. Aust. J. Agric. Res., 40(1):125-136.

WILSON, J.R., MERTENS, D.R. 1995. Cell wall accessibility and cell struture limitations to microbial digestion of forage. Crop Sci., 35(1):251-259.

WILSON, J.R., ANDERSON, K.L., HACKER, J.B. 1989a. Dry matter digestibility in vitro of leaf and stem of buffel grass (Cenchrus ciliaris) and related species and its relation to plant morphology and anatomy. Aust. J. Agric. Res., 40(2):281-291.

WILSON, J.R., BROWN, R.H., WINDHAM, W.R. 1983. Influence of leaf anatomy on the dry matter digestibility of $\mathrm{C}_{3}, \mathrm{C}_{4}$, and $\mathrm{C}_{3} / \mathrm{C}_{4}$ intermediate types of Panicum species. Crop Sci., 23(1):141-146.

WILSON, J.R., DEINUM, B., ENGELS, F.M. 1991. Temperature effects on anatomy and digestibility of leaf and stem of tropical and temperate forage species. Neth. J. Agric. Sci., 39(1):31-48.

WILSON, J.R., AKIN,D.E., McLEOD, M.N. et al. 1989b. Particle size reduction of the leaves of a tropical and temperate grass by cattle. II. Relation of anatomical struture to the process of leaf breakdown through chewing and digestion. Grass Forage Sci., 44(1):65-75.

Recebido em: 20/10/98 Aceito em: 20/07/99 